\title{
Migración y trabajo, una revisión del contexto chileno actual
}

\author{
Migration and labour, a review of the current Chilean context
}

\author{
Diego Rival-Carrillo \\ Universidad de Concepción, Chile \\ Amanda Valenzuela-Valenzuela \\ Fundación Kimntrum, Chile \\ Ricardo Cartes-VelásQuez \\ Fundación Kimntrum, Chile
}

RESUMEN Los flujos migratorios son parte de la historia de Chile, y han tenido cambios a través del tiempo. Actualmente, existen múltiples vulneraciones a los derechos de las personas migrantes, que conllevan a que tengan dificultades para acceder a la esfera laboral. Esto dificulta cumplir el objetivo principal de la migración, correspondiente a mejorar las condiciones de vida. Se exploran en esta revisión bibliográfica los principales motivos para abandonar las naciones de origen; la etnicidad, diversidad cultural y procesos de aculturación; la vulneración de derechos de personas migrantes, destacándose las vulneraciones legales; y el trabajo como fenómeno social, donde se incluye la relevancia de los cursos y talleres de formación laboral para la población migrante. Se concluye que a través de múltiples intervenciones pueden disminuirse las vulneraciones de derechos a las personas migrantes y mejorar sus condiciones de vida, facilitando su acceso a la esfera laboral.

PALABRAS CLAVE Aculturación; inmigración; migración; migración laboral; productividad laboral. 
ABSTRACT Migratory flows are part of Chilean history, and have experienced changes throughout the years. Nowadays, there are multiple violations to migrants' rights, which hinder their access to employment. This goes against migration's main purpose, which is to improve one's living conditions. This review explores the main reasons that lead migrants to leave their nations of origin; ethnicity, cultural diversity and acculturation processes; migrants' rights violations, highlighting legal rights violations; and employment as a social phenomenon, in which training courses and workshops become extremely relevant for migrant population. It is concluded that through multiple interventions, migrants' rights violations might be diminished, improving their living conditions and facilitating their access to employment.

KEYWORDS Acculturation; immigration; migration; labor migration; labor productivity.

\section{Introducción}

La migración puede definirse como los traslados no coyunturales de determinada población a través de regiones o territorios delimitados (Malgesini y Giménez, 200o). En Chile, como en el mundo, los procesos migratorios se han dado históricamente, y pueden calificarse de dinámicos, puesto que las cifras y nacionalidades de las personas han mutado en el tiempo (Silva, 2006). Chile se encuentra en presencia de grandes flujos de migrantes desde variados países del mundo. Se destaca la población latinoamericana, correspondiente a la región de origen de la mayoría de las personas inmigrantes, en particular los países de Venezuela, Perú, Haití, Colombia y Bolivia (Instituto Nacional de Estadísticas y Departamento de Extranjería y Migración [INE y DEM], 2019). Estos flujos de migrantes han originado una serie de consecuencias en el tejido social, tanto del país receptor como los países de los actores que llegan, debido a la interacción de distintos grupos culturales (Arenas y Urzúa, 2016; Correa, 2011; Mora, 2008). La tendencia en los migrantes muchas veces no apunta hacia la mejora de las condiciones de vida, sino que a mantenerlas o empeorarlas (Fundación Techo, 2015; Stefoni, 2011).

Hoy en día, se busca el respeto, la tolerancia y la valoración de la diversidad cultural, tanto desde los estamentos públicos como los privados, desde la sociedad en conjunto (Bonfil, 1988; Stefoni, Stang y Riedemann, 2016). No obstante, persisten situaciones de discriminación hacia las personas migrantes, que en conjunto a otros factores las ponen en situaciones de precarización y vulnerabilidad social (Arenas y Urzúa, 2016; Bonfil, 1988; Correa, 2011; Mora, 2008). Un ejemplo es la precaria oferta laboral para personas inmigrantes, pese a que la búsqueda de trabajo es una de las principales razones para migrar (Fraser, 2006; Matta, 2017; Postigo, 2011; Ruíz, 2016; Stefoni, Leiva y Bonhomme, 2017; Thayer, Córdova y Ávalos, 2013). 
Por lo anterior, es que el objetivo de este artículo es describir algunos de los elementos fundamentales para discutir la integración de la población migrante a la fuerza laboral chilena, en base a una revisión bibliográfica. Para esto, se presentará primeramente el concepto de migración, el contexto en que se da y las principales motivaciones para abandonar el país de origen. Luego, se abordarán los conceptos de etnicidad, diversidad cultural y aculturación, definiciones clave para poder estudiar los efectos de la migración en los actores involucrados. Esto será seguido por la presentación de la vulneración a migrantes, sus principales factores y consecuencias. Como cuarto elemento, se aborda el trabajo como fenómeno social, donde se recalca la relevancia de los cursos de formación para la población migrante, ya sea en el idioma como en el contexto laboral. El quinto apartado corresponde a una descripción más detallada de la capacitación laboral dirigida a migrantes en Chile. Se finaliza con una discusión de la evidencia empírica revisada, utilizando los conceptos previamente mencionados.

\section{Contexto y principales motivaciones para abandonar el hogar}

En Chile, los procesos migratorios se han dado históricamente, y pueden calificarse de dinámicos, puesto que las cifras y nacionalidades de las personas se han transfigurado en el tiempo. Según el INE y DEM (2019), el 7,12\% del total de la población chilena corresponde a población extranjera. Entre estas personas migrantes, alrededor del 60\% de las personas se encuentran entre los 20 y 39 años de edad, es decir, en su etapa de mayor productividad laboral. Los grupos con mayor presencia en nuestro país provienen de Venezuela, Perú, Haití, Colombia y Bolivia. En la Región del Biobío, de acuerdo al INE (2017).

Puede apreciarse, entonces, que la población migrante con mayor prevalencia en Chile corresponde a latinoamericanos. Entre las posibles causas de las migraciones hacia Chile, se encuentra el hecho que este es considerado uno de los países más estables de la región, por lo cual se vuelve atractivo para otros países de América Latina que atraviesan una situación de vulnerabilidad e inestabilidad mayor que la chilena (Matta, 2017; Silva, 2006). Otros factores detectados como causas para la migración corresponden a la globalización, la búsqueda de trabajos mejores a los que pueden acceder en su país de origen, situaciones de violencia y condiciones medioambientales que afectan al vivir de las personas (Agencia de la ONU para Refugiados, 2017; Álvarez, 2004; Held, McGrew, Goldblatt y Perraton, 2002; Matta, 2017; Oetzel y Ruiz, 2017; Peña, 2018).

Como primer punto a desarrollar, debe considerarse la vulnerabilidad latinoamericana. Esta corresponde a una motivación socioeconómica para migrar del país de origen, que atrae a los migrantes por condiciones que parecen favorables en Chile (Matta, 2017). Esto ocurre, sin considerar el hecho que existe una tendencia de mar- 
ginalizar a la población migrante, como ocurre debido al problema habitacional que lleva a las personas extranjeras a tomarse terrenos (Frías, 2017; Fuentes, 2018; Fundación Techo, 2015).

Por otro lado, la globalización como causa, surge desde la concepción del mundo como un espacio social compartido, donde se hacen difusos los márgenes entre las naciones. En este contexto, lo acontecido en un lugar del mundo tiene consecuencias tanto para comunidades como individuos de otra región de este (Castro, 2005; Held et al., 2002). Por ello, se dice que existe una interconexión entre todos los puntos del planeta, donde se destaca la transversalidad de las fuerzas económicas. Esto se asocia al concepto de sociedad global, donde el mundo entero es considerado un sistema social singular, producto de interacciones sociales a escala mundial (Silva, 2006). Sin embargo, pese a esta globalización, las fronteras de mayor relevancia y menor visibilidad continuarán estando presentes. Según Ortín (2013), estas corresponden a las fronteras mentales, afectadas por el proceso de globalización, cuyos efectos van más allá de lo económico, destacándose aquellos intangibles en la construcción mental del "ellos" y el "nosotros".

A su vez, la globalización se asocia a la Teoría de la Transnacionalización, en la cual las comunidades migrantes son vistas como una respuesta hacia fenómenos más globales, y se encuentran simultáneamente entre su país de origen y su país receptor (Castro, 2005). Por ello, no debe considerarse que existe una interacción de dos comunidades aisladas, sino que surge una comunidad desde la transnacionalización de determinadas estructuras, como las políticas, económicas y culturales, a través de la migración. Así, quienes migran no han roto los vínculos con sus países o sociedades de origen, sino que mantienen relaciones económicas, sociales y políticas, simultáneamente a su adaptación a la sociedad receptora (Moraes, 2006). La transnacionalización cobra especial relevancia al considerar que, actualmente, los grupos tienden cada vez más a juntarse y generar comunidades o agrupaciones, sin perder los lazos con su lugar de origen.

Otra importante causa para la movilidad de personas entre fronteras radica en la búsqueda de un trabajo mejor al que pueden acceder en su país de origen, respaldado en las cifras presentadas por el INE y DEM (2019), en que se evidencia el importante porcentaje de personas migrantes en su edad de mayor productividad laboral. Sin embargo, por sobre esta causa se encuentran los contextos de violencia que llevan a las personas a abandonar sus países de manera forzada. Esto ocurre de forma global, estimándose hace dos años que la cifra de población movilizada forzadamente alcanzaba 68,5 millones de personas (Agencia de la ONU para Refugiados, 2017), de los cuales varios millones se encuentran en Latinoamérica. Un ejemplo de la región es el caso de Colombia, país que vivió un importante conflicto armado y crisis política, considerado el desplazamiento forzado más característico de Latinoamérica (Álva- 
rez, 2004). Actualmente, la situación colombiana ha mejorado considerablemente, pero se presenta una movilización masiva por parte de la población venezolana, debido a la violencia política que se vive en ese país, que ha llevado a un éxodo de personas hacia todos los países del resto de Latinoamérica (Peña, 2018). En el caso colombiano, un estudio realizado en la ciudad de Santiago de Chile (Rihm y Sharim, 2017), el que abordó los motivos de catorce migrantes colombianos para abandonar su país de origen, se comentan la pluralidad de las causantes de migración, comenzando con el deseo de autoafirmación, siendo un concepto clave el "comenzar de cero". Una segunda causa a destacar es la necesidad de "más oportunidades", lo que no significa estar en situación vulnerable o de desesperación, pero si con necesidad de acceder a mejores y más oportunidades de mejorar las condiciones de vida, ante esto se relaciona el concepto de "salir adelante" y "reto personal". También destaca la necesidad de "desarrollo y crecimiento personal" por parte de los migrantes colombianos (Rihm y Sharim, 2017). En este mismo tema, en un estudio de Gissi, Pinto y Rodríguez (2019), donde se entrevistaron a cincuenta migrantes colombianos (hombres y mujeres de diversa edad), las causas de migración se relacionan con imaginarios sociales atribuidos a Chile, donde destacan tres: seguridad, calidad de vida y mayor acceso al trabajo. La estabilidad económica y política de Chile, como mayor seguridad que en países como Colombia o Brasil, que ha sido un destino frecuente para colombianos, es la que ha producido que Chile se convierta en destino predilecto para las personas de esta nacionalidad. En el caso venezolano, según Salgado, Contreras y Albornoz (2017), las tres principales motivaciones para abandonar el país fueron: situación económica de Venezuela (17\% hombres y $23,4 \%$ mujeres), inseguridad, sobre todo miedo a asaltos y secuestros (10,6\% hombres y $14,9 \%$ mujeres) y crisis política y social $(8,5 \%$ hombres y mujeres).

Finalmente, se encuentran las movilizaciones forzadas por condiciones medioambientales del planeta, que se ven afectadas tanto por desastres naturales como por los efectos del calentamiento global. Debido a la situación ambiental global actual, esta causa cobrará mayor importancia con el paso de los años. A la fecha, "más de 19 millones de personas tuvieron que abandonar sus hogares por inundaciones, tormentas y terremotos, que significa una cifra hasta cuatro veces superior a las migraciones por conflictos armados" (Oetzel y Ruiz, 2017). Esto puede ejemplificarse en el territorio latinoamericano con el caso haitiano. Además de complejos conflictos políticos y la fragilidad de sus instituciones, el año 2010 vio a Haití devastado por un terremoto, que llevó a sus habitantes a migrar al extranjero (Thomaz, 2013). Villanueva (2014) afirma que las principales motivaciones a trasladarse hasta Chile son variadas, donde destacan el querer mejorar la calidad de vida, mejora en términos sociales y económicos, además señala que muchos entraron a Chile en calidad de refugiados, esto posterior al terremoto de 2010. Así mismo, otro factor a resaltar es la inseguridad pública, 
como la inestabilidad política, uno de los jóvenes que da su testimonio comenta que "quiere vivir en un lugar donde pueda decir lo que piensa... despertar en la mañana y no ver que hay un golpe militar" (Villanueva, 2014). En la misma línea, Madariaga (2020) dice que el explosivo aumento de población migrante en Chile se dio posterior al terremoto del 2010 en Haití, siendo este uno de los principales motivos a migrar, esto ratificado en las entrevistas, además este factor natural acrecentó las condiciones de pobreza preexistentes. Otra causa que aparece reiterativamente en las entrevistas de este estudio, tiene que ver con las condiciones de inseguridad e inestabilidad política en el país caribeño.

\section{Etnicidad, diversidad cultural y aculturación}

Un punto importante de los procesos migratorios, consiste en la formación de un contexto de diversidad cultural. Este se caracteriza por la convivencia de más de un grupo cultural, y la interacción entre estos. Asociado a este concepto, se encuentra el de "grupo étnico", conformado por personas que se autoadscriben a una etnia y son identificadas por otras personas como parte de dicha etnia, entendiéndose la autoadscripción étnica como una elección válida para determinar la pertenencia étnica (Barth, 1969; Peyser y Chackiel, 1999). Desde esta definición, y en el contexto migratorio, un grupo étnico corresponde a una nación desterritorializada; aún si se encuentra en territorio extranjero, corresponde a una comunidad cultural (Gavilán, 2015).

En este contexto migratorio, se genera la interacción entre diversas etnicidades, lo cual da paso a complejos procesos entre las personas que participan de estas diversidades. El proceso principal es la configuración de identidades, donde se destaca la construcción de la alteridad. Esta se origina en que las personas inmigrantes llegan con sus nociones propias de identidad, las cuales no siempre coinciden con las nociones propias de la sociedad de llegada (Mora, 2008). Desde esto, se genera una diferenciación entre quienes habitaban el territorio con anterioridad y quienes llegan al mismo. En base a esta diferenciación, la sociedad de llegada comienza a delimitar lo que es el "nosotros", integrado por todo aquello que se considera propio de la nación, ya sea cultural o estéticamente, distinguiéndose de "los otros" (Correa, 2011). Las principales consecuencias de esta distinción y separación entre quienes migran y quienes habitaban el territorio previamente, son el racismo y la xenofobia por parte de las sociedades receptoras de migrantes, consecuencia considerada común en situaciones de migración. Estas distinciones surgen tempranamente en la vida de las personas, incluso desde el contexto escolar.

En este contexto, debe entenderse la educación como un proceso de transmisión cultural, principal responsable de la reproducción de identidad nacional y cultura cívica, con lo cual se norman a los distintos grupos culturales que pasan por ella (Larraguibel, 2017; Pérez, 1998). La educación tiene la tendencia de reproducir o asi- 
milar la cultura dominante, representada por la sociedad receptora de las personas migrantes, lo que conlleva a la pérdida de identidad cultural de las minorías culturales que se encuentran presentes (Hernández, 2013). En síntesis, la educación no es sólo el proceso de enseñanza de conocimientos en distintas áreas, sino que también forma parte de un proceso complejo de transmisión de ideologías, donde la sociedad receptora tiende a dominar por sobre los grupos étnicos o culturales minoritarios, como lo son las personas migrantes. Esto es parte de la construcción de etnicidad y alteridad. A la vez que se construye la identidad y la alteridad en contexto migratorio, se comienza la interacción entre diversos grupos étnicos. Sin embargo, las relaciones formadas no siempre se dan de forma horizontal o igualitaria, generándose relaciones de subordinación entre los grupos que comparten un contexto determinado. Usualmente, son los grupos extranjeros los que se ven subordinados ante las sociedades receptoras, lo cual es evidenciado a través de discursos de odio en redes sociales u otros campos de opinión, y a través de las legislaciones y políticas públicas existentes en cuanto migración. Una forma de subordinación común, pero que pasa desapercibida, es la aculturación. Esta se entiende como el fenómeno resultante de la interacción entre grupos culturales diferentes, donde se generan cambios en los patrones psicológicos y culturales originales, ya sea de uno o de ambos grupos (Arenas y Urzúa, 2016). En otras palabras, algunos rasgos culturales propios son reemplazados por rasgos culturales ajenos. Generalmente, esto se da de forma que el grupo inmigrante reemplaza rasgos culturales propios por aquellos de la sociedad receptora. Con respecto a la aculturación de grupos migrantes en Chile, podemos señalar el caso de un estudio realizado por Arenas y Urzúa (2016) en la ciudad de Antofagasta, donde se entrevistaron a 232 ciudadanos colombianos, estos señalan que la estrategia de aculturación más utilizada por esta comunidad migrante es la biculturalidad, siendo un 30\% del total de las personas quienes afirman esto, en segundo lugar también se establece la separación de este grupo con los chilenos como segunda estrategia de aculturación con un $28 \%$ de los casos totales. Por otra parte, un estudio llevado a cabo por el Centro Nacional de Estudio Migratorios (CENEM) de la Universidad de Talca (2018), detectó que un 91,9\% de los extranjeros afirman mantener las costumbres de su país de origen, mientras que un $84,6 \%$ han adquirido costumbres de los chilenos. A partir de estos números, podemos afirmar que la principal estrategia de aculturación corresponde a la biculturalidad, donde las personas migrantes adquieren nuevas costumbres, pero siempre manteniendo las propias, al menos en términos muy mayoritarios.

Desde esto, Bonfil (1988) describe cuatro clases resultantes de las interacciones entre diversas identidades culturales. Estas son la clase cultural autónoma (el grupo toma decisiones sobre elementos culturales que son propios, porque los produce o conserva, sin mecanismos de control externos), la clase cultural impuesta (ni los elementos culturales ni las decisiones son propios del grupo, puesto que se toma como 
referencia otra cultura hegemónica), cultura apropiada (cultura de una sociedad cambia parcialmente al tomar partes o elementos culturales de otras sociedades, pero es incapaz de producir o reproducir estos caracteres culturales de manera autónoma) y cultura enajenada (elementos culturales propios del grupo, pero sobre los que no se tiene la capacidad de decidir, puesto que el control es ejercido por un grupo hegemónico). Estas clases no son opuestas entre sí, sino que tienden a darse de manera simultánea en mayor o menor grado.

El enfoque intercultural aparece como una alternativa a lo mencionado anteriormente, y es visto como la posibilidad de generar un encuentro igualitario entre grupos diversos, a través del diálogo y el compartir de posiciones y saberes (Stefoni et al., 2016). Esto surge en contraposición de la tónica anterior, consistente en la asimilación de las culturas por parte de la sociedad receptora hegemónica. Esto busca reproducirse en el contexto educativo, con la Ley General de Educación que reconoce la diversidad de estudiantes (Ley 20.360, 2009) y la Ley de Inclusión Escolar, que busca que todos los establecimientos educacionales sean inclusivos con las personas, sin importar su grupo étnico, cultural, nacional o religioso de procedencia (Ley 20.845, 2015). La relevancia de esto se ve en que el sistema educacional reflejará las condiciones políticas que son imperantes en la sociedad en cuestión (Muñoz, 1999), en este caso respecto a la migración.

\section{Vulneración de derechos de personas migrantes}

Como se ha mencionado anteriormente, las personas suelen migrar en búsqueda de mejores condiciones de vida. Sin embargo, la tendencia es que las personas inmigrantes, generalmente, no mejoran sus condiciones de vida, sino que estas se mantienen o empeoran. Un ejemplo se ve en la pobreza multidimensional, explorada en la CASEN del año 2013, en la cual, al año 2009, un 27,5\% de los chilenos se encuentra en pobreza multidimensional, versus un 26,6\% de los migrantes, situación que se invierte el 2013 con un $20,3 \%$ de los chilenos en esta situación vs. un $25,2 \%$ de los migrantes (Rojas y Silva, 2016). Por lo anterior y más, se considera que la población migrante es víctima de una constante vulneración por parte de la sociedad, que tiene diversas aristas.

Un primer aspecto a considerar, es el legal. La vulneración en el campo legal, se ve desde dos perspectivas principales, correspondientes a la regularidad legal en el país y a la criminalización de las personas inmigrantes. La regularidad legal es uno de los aspectos que más entorpece la integración de las personas inmigrantes, y contradice lo propuesto en cuerpos legales internacionales como la Declaración de Derechos Humanos. Ante esto, se considera que Chile no dispone de legislación que responda acordemente a dicho cuerpo legal, ni a la realidad migratoria que se vive hoy, puesto que el país no cuenta con una política pública que sea explícita respecto a la migración (Stefoni, 2011). De hecho, la Ley que actualmente rige al país en temáticas 
de migración corresponde al Decreto Ley 1.094 de 1975, concebido en la lógica de seguridad nacional, y causa que las personas inmigrantes sean vistas más como amenazas para el país que como sujetos de derecho, por lo cual son pasados a llevar sus derechos fundamentales y se precarizan sus condiciones de vida (Matta, 2017; Silva, 2006). Debe considerarse que la Ley existente, con sus más de cuarenta años de existencia, es reconocida como la más antigua de la región latinoamericana, por lo cual no responde a la situación migratoria contemporánea (Rojas y Silva, 2016). Por otro lado, las políticas públicas tienen como objetivo principal corregir los problemas de la sociedad para el beneficio colectivo, e implican un esfuerzo por parte de actores de la sociedad para procurar mejores condiciones de vida para las personas (Gómez, 2014; Rojas, 2008). Por ello, su ausencia es un hecho preocupante.

Así, la principal consecuencia de la irregularidad legal, es el poco o nulo acceso a derechos de las personas inmigrantes, lo cual entorpece el proceso de buen vivir de los migrantes. Se da que las personas migrantes son consideradas como inexistentes por la población receptora, lo cual se explica por la falta de estadísticas que den cuenta fidedigna de la cantidad de personas migrantes en el país, debido a la gran cantidad que inmigró de manera irregular y debe esconder su situación (Matta, 2017). De todas formas, se puede estimar que, del total del país, un 10\% de las personas residentes de manera permanente son inmigrantes en situación irregular, con lo cual se calcula que en Chile hay alrededor de 20.000 inmigrantes irregulares (Silva, 2006).

En cuanto a la criminalización de las personas inmigrantes, esta se evidencia desde la forma en que la clase política trata a la población migrante. Esto puede ejemplificarse desde la cobertura de prensa de las expulsiones masivas realizadas en el actual gobierno del Presidente Sebastián Piñera, donde canales de televisión transmitían en directo cómo migrantes de países vecinos eran embarcados en aviones y buses hacia sus países de destino. Los noticieros y periódicos destacan los procesos legales pendientes en el país de origen de las personas, y delitos cometidos en Chile (Muñoz, 2019), enunciando que son personas "que han venido a nuestro país a cometer delitos” (ADN Radio, 2018). Desde las agrupaciones de migrantes, se considera que esta política de expulsión masiva y pública genera un discurso de criminalización hacia las personas extranjeras, convirtiéndolas a todas en personas con intenciones de delinquir (El Dínamo, 2019). Además, las cifras indican que el 2015 se expulsaron del país a 2692 personas, principalmente bolivianos $(31,8 \%)$, colombianos $(25,8)$ y dominicanos $(23,7 \%)(D E M, 2015)$, esto mucho más que aquellas que fueron expulsadas en este último periodo de manera pública. Esto implica una intención política prejuiciosa hacia las personas inmigrantes, donde se busca destacar la criminalización como la única característica importante de quienes inmigran. 
Siguiendo en la criminalización de los grupos migrantes, podemos destacar el estudio hecho por Stang y Stefoni (2016), donde se entrevistó a personas de nacionalidad colombiana asentadas en Antofagasta. Las autoras destacan la relación entre el aumento de la delincuencia en dicha ciudad y el incremento de la comunidad colombiana, cuestión que es señalada por parte de algunos segmentos de los habitantes chilenos de dicha ciudad. Esta cuestión ha escalado a instancias políticas, siendo este discurso afirmado por diversos parlamentarios o instituciones u organizaciones sociales, como autoridades municipales. En base a este fenómeno, Stang y Stefoni (2016), destacan que esta realidad se genera en base a imágenes prejuiciosas que hablan de la toma de espacios como las calles o plazas, esto por focos de microtráfico y prostitución, que se ligan discursivamente a la comunidad colombiana.

Actualmente, existen iniciativas para combatir esta vulneración legal, como lo son las Clínicas Jurídicas de distintas instituciones u organizaciones, usualmente universidades, que facilitan la regularización legal de las personas, muchas veces de forma gratuita. De acuerdo a Matta (2017), las Clínicas Jurídicas se presentan como una herramienta para atender a la diversidad en aspectos que van, incluso, más allá de la regularización en el país. Se destacan en la capital las clínicas jurídicas de la Pontificia Universidad Católica de Chile, la Universidad Alberto Hurtado y la Universidad Diego Portales, valorándose positivamente el enfoque interdisciplinario de la Universidad Católica.

Otra vulneración importante es la situación habitacional, donde muchos de los migrantes que habitan en Chile terminan viviendo en nuevos campamentos o tomas de terreno. Esto se explica en el hecho que el acceso a la vivienda es históricamente limitado para la población migrante (Rojas y Silva, 2016). En el total de campamentos en Chile, se recalca que el 5,9\% de los pobladores tienen nacionalidad extranjera, destacándose Bolivia (32,4\%), Colombia $(32,3 \%)$ y Perú $(27,1 \%)$ como los países de procedencia con mayor cantidad de inmigrantes en campamentos, entre otros de Latinoamérica (Fundación Techo, 2015). Un ejemplo específico es Antofagasta, donde los campamentos se conforman por personas de clases medias-bajas, grupos emergentes y migrantes latinoamericanos (Fuentes, 2018). Por otro lado, en Santiago, está el campamento Ribera Sur de Colina, que alberga a 140 familias, cuya gran mayoría corresponde a personas inmigrantes de República Dominicana, además de personas provenientes de otros países (Frías, 2017). Se considera que, a través de la segregación, surgen campamentos exclusivamente de migrantes, lo cual puede apreciarse en la cantidad de extranjeros que habitan en campamentos en las regiones de Antofagasta $(32,8 \%)$, Arica y Parinacota $(27,4 \%)$, Tarapacá $(18,4 \%)$, convirtiéndose la zona norte en el sector más representativo de esta problemática (Rojas y Silva, 2016). 
Estas vulneraciones influyen directamente en la búsqueda de trabajo de las personas extranjeras que habitan en Chile. Lo anterior es relevante al considerar que la mayoría de las personas inmigrantes se encuentran en edad de trabajar, y presentan mayores niveles de estudios superiores que la población chilena (42,6\% de personas inmigrantes versus un 29,1\% de la población chilena) (INE, 2017). No obstante, el 62\% de los extranjeros se encuentran en empleos de mediana o baja calificación, por lo cual existe una subutilización de mano de obra calificada (Cárdenas, 2019). Además, la mayoría se encuentra en trabajos informales, con los cuales no tienen afiliación al sistema privado o público de salud (Rojas y Silva, 2016).

El hecho que la población migrante se vea forzada a trabajar en empleos de mediana o baja calificación se explica con las dificultades existentes para realizar la validación de estudios superiores, donde como primer obstáculo se encuentra la necesidad de contar con una cédula de identidad de extranjeros, documento que sólo puede ser emitido al haber obtenido una visa distinta a la turística (Ministerio de Educación, s.f.). La validación de estudios superiores puede realizarse en el Ministerio de Relaciones Exteriores (sólo los países que han firmado algún convenio al respecto con Chile), el Ministerio de Educación (títulos obtenidos en Argentina) y la Universidad de Chile (para aquellos países que no tienen convenio con Chile) (Adriasola, 2016). Por lo anterior, el proceso de validación de título puede tomar meses o, incluso, años, en particular si consideramos que de los países con mayor número de inmigrantes, Bolivia, Perú y Colombia cuentan con convenio, pero Haití y Venezuela no.

En las validaciones realizadas por la Universidad de Chile, Cárdenas (2019) enuncia que se pasó de 321 solicitudes de revalidación el 2006 a 1.467 el 2018, desde lo que se desprende que la carga ha aumentado considerablemente para la única casa de estudios que realiza este trámite para quienes proceden de países sin convenio, trámite que tiene un costo asociado entre 15 y 20 UTM (Adriasola, 2016). Así, debido a las vulneraciones legales, las personas inmigrantes que tienen competencias profesionales, cuentan con dificultades para ejercer su profesión, incumpliéndose el objetivo principal de la migración, de mejorar las condiciones de vida. Finalmente, con esto se pierde la oportunidad de mejorar la productividad a través de esta mano de obra calificada, ya que no cuentan con títulos reconocidos (Cárdenas, 2019).

\section{Trabajo como fenómeno social}

El concepto de trabajo puede abordarse desde distintas perspectivas. De acuerdo a Cultelli y Sosa (2018), el trabajo corresponde a la actividad humana encaminada a un fin determinado, a la creación de bienes materiales e inmateriales, útiles. En base a esto, existe el trabajo concreto y abstracto. Desde lo concreto, el trabajo crea cosas que son socialmente útiles (Antunes, 2000, p. 91), entendiéndose lo útil como una definición social propia de cada grupo cultural. Por otro lado, el trabajo abstracto se 
reduce al gasto de fuerza humana, ya sea en lo físico o intelectual, para llevar a cabo un trabajo específico, con lo cual la fuerza productiva se convierte en una mercadería con el fin de crear nuevos productos, con vistas a la obtención de lucro (Gomes y Elizalde, 2009; Neffa, 2015).

La Teoría del Valor-Trabajo surge de estos tipos de trabajo, que le otorgan valor social y de cambio a las mercancías. Una perspectiva de esta teoría indica que los precios de mercadería se determinan por la cantidad de trabajo realizado (Sánchez y Montibeler, 2015), con lo cual la fuerza de trabajo se convierte en una mercancía que puede ser vendida (Garza, 1997). No obstante, esta visión no abarca la valoración social del trabajo ni la evolución de la tecnología desde la época de su concepción, durante la revolución industrial.

Respecto a la valoración social, esta puede entenderse como la valoración social del aporte de sujetos a la producción de bienes y servicios, ligado al reconocimiento y la aceptación de identidades culturales diferenciadas en este proceso (Fraser, 2006; Thayer, 2013). Esto se da gracias a que la distinción entre trabajo y no trabajo son definidas socialmente, sujetas a modificaciones cuando las relaciones de fuerzas económicas y sociales cambian (Garza, 2001). Se desprende que aquellos grupos que no encajan en los patrones de las identidades culturales aceptadas, no son reconocidos, con lo que disminuye su valoración social. Esto afecta a los grupos minoritarios existentes en nuestra sociedad, que son desprestigiados injustamente, debido a la distribución económica y al orden de estatus asignado por la sociedad (Fraser, 2006; Postigo, 2011).

En estos grupos no reconocidos, se destaca la población migrante, por ser grupos altamente estigmatizados, debido a la racialización que se produce desde las sociedades receptoras hacia las personas originarias de determinados países (Fraser, 2006). En el caso chileno, se considera que la población local busca distanciarse de inmigrantes de origen andino, y acercarse de inmigrantes de origen europeo, o descendientes de los mismos (Thayer, 2013). Es así que, a la hora de buscar empleo, las personas inmigrantes de los grupos estigmatizados se ven forzadas a aceptar trabajos de poco valor de cambio (poca retribución económica), pese a que suelan tener alta valoración social (cuidado de niños, niñas y adultos mayores, entre otras labores).

Actualmente, nos encontramos en un sistema neoliberal, lo que significa un quiebre del modelo fordista existente anteriormente, en el que las jornadas de trabajo estaban reguladas, tenía una duración indefinida en el tiempo, y contaba con un mínimo de protección jurídica para los trabajadores (Caamaño, 2005). Sin embargo, el sistema actual se caracteriza por la precarización del trabajo, con un neoliberalismo que se basa en la ampliación del capitalismo, la mercantilización de la vida social, y la privatización de la propiedad pública (Ruíz, 2016), con lo cual se evidencia que el sistema neoliberal influyó en las formas de producción. Surgen empleos con condi- 
ciones laborales poco estables, donde suele insertarse la población migrante trabajadora, agudizándose en esta la precarización del trabajo (Luján, 2009; Ruíz, 2016). Esto se explica con lo expuesto anteriormente sobre las dificultades de validar estudios (Adriasola, 2016; Cárdenas, 2019), y se ejemplifica con la realidad de trabajos en la industria de la construcción, expuesto por las autoras Stefoni et al. (2017), en un estudio llevado a cabo en Antofagasta. Para las autoras antes mencionadas, la participación de la población migrante en la industria de la construcción chilena es una situación provechosa para empleadores por la reducción de costos asociados a la contratación de personal, quienes ofrecen empleos precarios e inestables, que las personas migrantes aceptan para generar suficientes ingresos para vivir (Stefoni et al., 2017).

Continuando con la realidad laboral de las comunidades migrantes en Chile, podemos destacar un estudio exploratorio confeccionado por el Ministerio de la Mujer y Equidad de Género (MIMEG), quienes en el año 2017 encargaron dicha pesquisa para conocer la realidad del trabajo migrante. El estudio muestra que la realidad laboral de las mujeres migrantes es bastante peor que la de los varones, por su condición de género. La existencia de hijos y muchas veces el estar a cargo sola de ellos acentúa más la precarización del trabajo migrante. En el caso de mujeres colombianas, buena parte de ellas cuenta con títulos técnicos y educación secundaria, sin embargo, existe desclasificación de estas personas, desempeñándose en trabajos informales como comercio ambulante y estética, cuestión parecida se observa en el caso de las mujeres venezolanas, quienes a pesar de eso acceden a mejores empleos con respecto a las demás comunidades de migrantes presentes en Chile (Ministerio de la Mujer y Equidad de Género, 2017). Dicho informe habla de una realidad de las mujeres migrantes en su generalidad de precarización e informalidad del trabajo de dichas comunidades.

Lo anteriormente expuesto, puede explicar uno de los hallazgos de la Encuesta de Caracterización Socioeconómica Nacional (CASEN) (Ministerio de Desarrollo Social, 2017), en que se revela que la participación laboral en Chile de personas migrantes corresponde al $81,3 \%$ de los mismos, superando al $58,3 \%$ de la participación laboral de personas chilenas. En base a lo expuesto, la participación laboral de migrantes es superior a la de personas nacidas en el país, pero se concentra en trabajos precarios e inestables. Por ello, y por la imposibilidad de ejercer en sus profesiones u oficios estudiados en sus países de origen, se vuelve relevante la formación laboral en distintos oficios y temáticas.

Actualmente, se han realizado múltiples intervenciones a las personas migrantes, debido a que es un grupo de la población considerado vulnerado por la sociedad. El objetivo de estas intervenciones es mejorar las condiciones de vida y cambiar la realidad de vulneración de derechos en que viven. Así, surgen los cursos de formación laboral o capacitación en oficios varios. 
A modo de contextualizar el surgimiento de cursos de formación laboral, debe abordarse la realidad europea, donde grandes masas de personas de Medio Oriente y del Norte de África abandonan sus hogares, y se trasladan hacia países del mediterráneo. Estas personas migrantes se ven en la obligación de abandonar sus hogares por los conflictos armados de Medio Oriente y por la situación de pobreza del continente africano, es decir, emigraron en búsqueda de mejorar sus condiciones de vida. Sin embargo, este proceso migratorio causó un aumento dramático de la cantidad de personas detenidas por falta de empleo en el continente europeo, originando así un grupo gigante de personas que vive en situación de vulneración de derechos, sin lograr cumplir el objetivo original de la migración.

Desde lo anterior, no es sorprendente que una las principales consecuencias de la migración es el poco o nulo acceso de la población migrante a los derechos básicos, situación que se repite tanto en Europa como en Latinoamérica (OIT, 2016), por desinformación. Este acceso o falta de acceso a derechos básicos puede verse a través del Migrants Integration Policy Index (MIPEX), el cual, como plantea Kogan (2016), mide la forma en que ciudadanos irregulares o personas en situación de migración tienen derecho a la igualdad de derechos y acceso a los mismos, a través del Estado receptor. La autora añade que, para este fin, el MIPEX evalúa leyes y políticas sobre la movilidad en el mercado laboral, residencia a largo plazo, participación política y la lucha existente contra la discriminación. Por lo tanto, este índice es una herramienta útil para evidenciar cómo los países tratan la migración, ya que evalúa la eficacia de las políticas. Lamentablemente, este índice se encuentra desarrollado para países con mayor tradición de migración, dejando fuera a Latinoamérica. Sin embargo, actualmente se está trabajando en una adaptación de MIPEX para Latinoamérica, en base a la metodología europea (Diálogo Político, 2018). En cuanto a la relación del MIPEX y el trabajo de las personas inmigrantes, se identifica que no hay una relación fuerte y directa entre ambas variables, destacándose los subsidios salariales como el factor con mayores resultados en la lucha contra la vulneración de las personas migrantes (Kogan, 2016).

Ya abordando la incorporación laboral, se destacan los Países Bajos y Noruega como los dos países con mejor integración de personas migrantes, contratando a quienes poseen buena formación, o dándoles la posibilidad de participar en capacitaciones laborales; por otro lado, Suecia, Portugal y España son los países que incluyen personas con menor capacitación en su mercado laboral (Kogan, 2016). De esto se concluye que en los Países Bajos y Noruega las personas migrantes tendrán la posibilidad a acceder a trabajos con mejor valor de cambio y valoración social, mientras que en Suecia, Portugal y España tendrán que realizar trabajos más precarios. Esta información es relevante para ver qué puede hacerse en países latinoamericanos para mejorar la recepción de personas migrantes. 
En respuesta a esto, surgen distintas intervenciones para mejorar las condiciones de vida de las personas inmigrantes, particularmente en el ámbito laboral. Sin embargo, pese al extenso abordaje desde las ciencias sociales a la situación de personas migrantes, intervenciones como las capacitaciones laborales han sido mucho menos estudiadas. De todas formas, en Barcelona, Yufra (2013) realizó una sistematización sobre las instancias de capacitación laboral. La autora destaca que se reconoce la existencia de migrantes deseados y de migrantes no deseados. Los migrantes deseados son aquellas personas que poseen ciertos rasgos valorados positivamente, como su interés por la inclusión en el campo laboral como la supresión de rasgos culturales propios. En esta aculturación, se facilita la inserción de las personas migrantes en la sociedad receptora. Un ejemplo dado en la investigación de Yufra (2013), son las personas musulmanas, quienes por motivos religiosos interrumpían sus labores para rezar en determinados momentos del día. Si bien en el trabajo de la autora no se plantea la necesidad de eliminar los rezos de los migrantes árabes en España, si queda implícito ante las quejas de una persona entrevistada sobre las salidas periódicas desde sus puestos de trabajo. Por ello, se considera que "las particularidades culturales o religiosas de las personas inmigrantes deben ser dejadas de lado, o, mejor aún, eliminadas desde el punto de vista de algunos de los servicios de formación para la inserción sociolaboral" (p. 191).

Posteriormente, en otra investigación realizada por Yufra y Santamaría (2015), se destaca que algunas de las instituciones que imparten cursos de oficio o capacitación laboral tienden a presentar discriminaciones de género, donde las mujeres inmigrantes se encuentran "destinadas" a la realización de trabajos de alta valoración social pero poco valor de cambio, como el cuidado de niños, niñas y adultos mayores, con un pago bajo excusado en la crisis económica española. En general, se da que los rubros u oficios enseñados son de baja valoración social o considerados trabajos indeseados por la población española. Así, las personas migrantes pasan de ser sujetos indeseados por la sociedad receptora a ser sujetos deseados, puesto que se hacen cargos de labores que son rechazadas por personas originarias de España.

\section{Capacitación laboral en Chile}

Ya en Chile, se han abierto múltiples instancias para la inserción laboral de migrantes, donde se destaca la formación en cursos de oficio o capacitaciones laborales. Sin embargo, estas respuestas para facilitar la integración laboral a las personas en situación de migración son desconocidos o ajenos a la opinión pública, similar a la realidad internacional.

Como primer ejemplo de una instancia de capacitación o formación laboral chilena, se encuentra la escuela culinaria para migrantes, dictada por una entidad privada, la Universidad de Las Américas (EMOL, 2018). Por otro lado, desde el gobierno, nace 
la inclusión sistemática de migrantes en los cursos impartidos por el Servicio Nacional de Capacitación y Empleo (SENCE). Esta inclusión en cursos SENCE se dio a nivel nacional, y se dirigía a personas que no contaban con la visa permanente en Chile, con el compromiso de facilitar la tramitación del documento a quienes completaban el 25\% del curso (Asencio, 2017). Internacionalmente, este tipo de instancias están reservadas a personas con situación de residencia permanente resuelta, con lo cual Chile se convierte en un país pionero al incluir personas que aún no cuentan con su visa (El Mercurio, 2017).

Respecto a estos cursos SENCE, realizados prácticamente en todas las regiones del país, a través de un diagnóstico cualitativo que incluyó la percepción de usuarios y de organismos capacitadores, se concluye que los cursos de capacitación actúan como una herramienta que mejora las posibilidades de inserción de las personas migrantes, tanto en el ámbito social como laboral (Asesorías para el Desarrollo, 2018). No obstante, en el mismo diagnóstico, se considera que las horas lectivas no son suficientes para profundizar el total de conocimientos. También se recomienda el diseño de un programa que contenga como principios orientadores "la integración económica y social de la población migrante. Se recomienda incorporar un enfoque de integración, inclusión e interculturalidad" (Asesorías para el Desarrollo, 2018).

Otro tipo de capacitaciones que se han vuelto relevantes en el contexto nacional, corresponden a aquellas que se enfocan en la enseñanza del idioma oficial, situación que se ha repetido en otros países receptores de migrantes, donde la preocupación por el contacto lingüístico producto de los movimientos migratorios ha sido una constante desde la década de los '6o (Hernández y Villalba, 2005; Mateo, 1995). En el contexto chileno, se ha dado históricamente que las poblaciones que inmigran provienen de otros países latinoamericanos, que ya son hispanohablantes. No obstante, esto cambia recientemente, con la migración de personas provenientes de Haití, cuyo idioma natal es el creole. Esto ha generado múltiples problemas de comunicación, como lo es el caso de una mujer haitiana acusada erróneamente por abandono de menores, situación que no logró rebatir por no hablar español, y que conllevó a su fallecimiento dentro de la comisaría en que se encontraba detenida (EMOL, 2017). Desde entonces, han surgido nuevas iniciativas desde organizaciones privadas para enseñar el idioma español a estos nuevos residentes de Chile. Debe destacarse que, si bien existen instancias de enseñanza del español como Segunda Lengua (ESL), gran parte de las personas dedicadas a esto son voluntarios sin formación en la adquisición de segundas lenguas, y que dictan las clases enteramente en español (Toledo, 2016). 


\section{Discusión}

La vulneración a las personas inmigrantes surge de distintos factores, como lo es la discriminación y la falta de acceso a derechos o trabajo. La discriminación encuentra su explicación en el racismo y la xenofobia que surgen desde la construcción de la alteridad, en la cual las personas nacidas en Chile se diferencian a sí mismas de las personas inmigrantes, debido a las fronteras mentales existentes y a las nociones de identidad de cada grupo (Correa, 2011; Mora, 2008; Ortín, 2013). Esto se asocia a los conceptos de etnicidad y diversidad cultural, que han sido abordados desde distintos enfoques en la historia de nuestro país, destacándose la autoadscripción como criterio para pertenecer a una etnia u otra, sin importar el territorio en que se encuentre la persona (Barth, 1969; Gavilán, 2015; Peyser y Chackiel, 1999).

Esta falta de derechos se explica por la falta de políticas públicas que regulen la situación de las personas migrantes desde una perspectiva de Derechos Humanos (Stefoni, 2011). Esto convierte a las personas migrantes en un grupo estigmatizado, por lo cual son consideradas como personas de bajo valor social (Fraser, 2006; Postigo, 2011). Esto se debe a que las políticas y la legislación existentes no están actualizadas, y fueron creadas desde la perspectiva de la Seguridad Interior en el periodo de dictadura, perspectiva que ve a las personas inmigrantes como amenazas para el país (ADN Radio, 2018; El Dínamo, 2019; Matta, 2017; Muñoz, 2019; Silva, 2006). Por ello, se considera a las dificultades para regularizar la situación legal de las personas que llegan al país como el origen de esta falta de derecho, ya que existen barreras para legalizar su situación y convertirse en ciudadanos, por lo cual no pueden hacer valer sus derechos básicos (Kogan, 2016; Stefoni, 2011).

La vulneración de derechos puede presentarse en distintos ámbitos de la vida cotidiana, como lo es el contexto educativo, entendido como una forma cultural en sí misma que tiene un rol fundamental en la transmisión cultural (Pérez, 1998). Sin embargo, en este contexto, la interculturalidad surge desde la preocupación por la identidad de los pueblos originarios, pese a que sus normativas pueden aplicarse a las personas migrantes (Ley 20.360, 2009; Ley 20.845, 2015).

En cuanto a salud, el acceso se ve limitado por la incapacidad de inscribirse en los dos principales modelos de proveedores de salud, ISAPRE y FONASA, pese a que actualmente existe un convenio en el cual se establece que las personas migrantes pueden acceder a FONASA para atenderse en el sistema público, si es que ya se encuentran tramitando su visa (Rojas y Silva, 2016). Además, las barreras existentes pueden ser sorteadas con un manejo apropiado del idioma, que no es el caso de las personas que inmigran de países no hispanohablantes, como Haití. Para sortear esta barrera, desde el Ministerio de Salud de Chile (MINSAL) se implementa en algunos establecimientos de salud una iniciativa, en la cual se busca la facilitación lingüística entre funcionarios del sistema de salud y usuarios haitianos que tienen el creole como 
lengua materna. Se esperaba en esta iniciativa que los funcionarios del sistema de salud pública supieran frases, preguntas frecuentes e instrucciones del sistema de salud en creole, con la ayuda de algunos médicos haitianos en la traducción y mediante un curso online (MINSAL, 2018). Si bien esta iniciativa fue valorada positivamente, no se extendió a todos los centros de salud pública, sino que se radicó en algunos. Actualmente, esto se está trabajando, particularmente a nivel de atención primaria de salud. También debe destacarse que el manejo de competencias interculturales por parte de los equipos de salud, son fundamentales para la atención holística a distintos grupos culturales (Veliz-Rojas, Bianchetti-Saavedra y Silva-Fernández, 2019), competencias entre las cuales se incluye el manejo del idioma.

En vivienda, producto de la marginalización se da que las personas migrantes se ven forzadas a habitar en campamentos o en situaciones de hacinamiento. Esto es peor en el sector norte del país, donde la cantidad de migrantes que habitan en campamentos es mayor que en el resto del país (Rojas y Silva, 2016). Esto puede solucionarse facilitando el acceso a las viviendas sociales para este grupo de la población, o a través de la intervención por parte de arquitectos a estos campamentos, que valore la identidad cultural de quienes los habiten, e incluya la participación de agrupaciones y organizaciones varias (Meninato y Marinic, 2019).

En el ámbito laboral, se destacan las barreras existentes para validar los estudios profesionales de las personas inmigrantes, con lo cual se ven en la obligación de desempeñarse en empleos precarizados, para los cuales se requiere de la mínima cualificación (Stefoni et al., 2017). En busca de mejorar las posibilidades laborales de quienes inmigran a nuestro país, es que surgen distintas instancias de capacitación laboral, que se convierten en un impacto positivo en la vida de las personas inmigrantes (Asesorías para el Desarrollo, 2018; EMOL, 2018). En estas capacitaciones, las personas migrantes pueden aprender distintos oficios, con lo cual aumentan sus expectativas laborales, y disminuyen su condición de personas con vulneración de sus derechos fundamentales. Chile se destaca en este ámbito por incluir capacitaciones con financiamiento estatal que consideran a personas migrantes que no tienen resuelta su situación residencial (El Mercurio, 2017). Además, estas capacitaciones se comprometen a expeditar la regulación de la residencia de quienes las cursaban.

A través del trabajo en todos estos aspectos y más, las personas migrantes podrán acceder a sus derechos básicos, y, poco a poco, tener más autonomía en la nación receptora que es Chile para ellas. En síntesis, se podrán disminuir las vulneraciones de derechos y la estigmatización a este grupo de la población, que ya son parte del tejido social chileno. Con esto, se potencia la importante oportunidad que presenta la población migrante en Chile, para su desarrollo cultural y económico (Rojas y Silva, 2016). 
Si bien Chile significa un buen destino de migración para personas de nacionalidades latinoamericanas, esto se condice con la realidad de ser el país más neoliberalizado de la región, situación que ha permitido una desigualdad intrínseca en lo social, cultural y económico en Chile (Garretón, 2013). La migración precarizada juega un rol en la reproducción de los grupos económicos dominantes, quienes explotan la mano de obra migrante en pos de sus intereses económicos, esto puede relacionarse directamente con la estructura político y jurídica del país, la que es deficiente no solo en materia migratoria, sino también en la regulación del mercado económico y laboral, siendo una de las bases del sistema adoptado, como dice Boron (2003), presenta relaciones mercantiles sin mediación, siendo el mercado el regulador. Ante esto, no es de extrañar la vulneración de derechos fundamentales a los que se ven expuestos los migrantes, siendo una situación que se conjuga con la racialización, nacionalidad o género de las personas, imbricación que genera interpretaciones sociales que inciden directamente sobre la realidad laboral de las comunidades mentadas.

Sin duda, las implicaciones de las relaciones económicas y sociales, configuran la realidad de las personas migrantes en los países más neoliberalizados, sobre todo a través de mecanismos de jerarquización o estratificación de los grupos sociales dentro de Chile. Así, Madero y Mora (2011) usando como ejemplo la migración peruana en Chile, quienes de cierta manera han alcanzado un mayor poder económico a través de la formalización de sus actividades económicas, señalan que esto se debe a la inclusión de este grupo al mundo laboral chileno, cuestión que puede contraponerse a lo revisado antes, donde, si bien existe una inclusión laboral, las condiciones son las que quedan en deuda, pues el trabajo migrante puede ser visto como explotación.

\section{Referencias}

Adriasola, Lucía (2016). Partir de cero: los migrantes que no pueden ejercer sus carreras en Chile. El Mercurio. Recuperado de http://www.economiaynegocios.cl/ noticias/noticias. asp?id=293119.

ADN Radio (2018). Gobierno concreta expulsión de 31 extranjeros con condenas en Chile. ADN Radio, versión online. Recuperado de http://www.adnradio.cl/noticias/nacional/gobierno-concreta-la-expulsion-de-31-extranjeros-con-condenasen-chile/20181121/nota/3827299.aspx.

Agencia de la ONU para los Refugiados (2017). Tendencias globales. Desplazamiento forzado en 2017. Ginebra, Suiza: ONU.

Álvarez, Raquel (2004). La dinámica migratoria colombo-venezolana: evolución y perspectiva actual. Revista Geoenseñanza, 9(2): 191-202.

Antunes, Ricardo (200o). La centralidad del trabajo hoy. Papeles de población, 6(25): 83-96. 
Arenas, Pablo y Alfonso Urzúa, (2016). Estrategias de aculturación e identidad étnica: un estudio en migrantes sursur en el norte de Chile. Universitas Psychologica 15(1): 117-128.

Asencio, Sebastián (2017). Gobierno lanza plan piloto para capacitar migrantes y regularizar estadía con nueva visa. Radio Biobío. Recuperado de: https://www. biobiochile.cl/noticias/nacional/chile/2017/o9/22/gobierno-anuncia-nueva-visaque-busca-capacitar-inmigrantes-y-regularizar-su-estadia.shtml.

Asesorías para el desarrollo (2018). Evaluación de implementación piloto de capacitación para personas migrantes 2017. Informe de resultados de la evaluación de implementación del programa. Santiago, Chile: Asesorías para el desarrollo.

Barth, Fredrik (1969). Ethnic groups and boundaries. The social organization of culture difference. Boston, Estados Unidos: Little Brown and Company.

Bonfil, Guillermo (1988). La teoría de control cultural en el estudio de procesos étnicos. Anuario antropológico (86): 13-53.

Boron, Atilio (2003). La sociedad civil después del diluvio neoliberal. En Sader, Emir y Gentili, Pablo (Coomps.). La trama del neoliberalismo. Mercado, crisis y exclusión social. CLACSO, Buenos Aires, Argentina.

Caamaño, Eduardo (2005). Las transformaciones del trabajo, la crisis de la relación laboral normal y el desarrollo del empleo atípico. Revista de Derecho, 18(1): 25-53.

Cárdenas, Rodrigo (2019). El 62\% de los profesionales migrantes está en empleos de menor calificación. Se piden cambios a revalidación de títulos. La Tercera. Recuperado de https://www.latercera.com/pulso/noticia/62-los-profesionales-migrantes-estan-empleos-menor-calificacion-se-piden-cambios-revalidacion-titu$\operatorname{los} / 722660 / \#$.

Castro, Yerko (2005). Teoría transnacional: revisitando la comunidad de antropólogos. Política y Cultura (23): 181-194.

CENEM (2018). Aculturación. Inmigrantes latinoamericanos y caribeños. Universidad de Talca, Chile.

Correa, Josefina (2011). Ser migrante en Chile: la experiencia del racismo cotidiano de los peruanos y peruanas en la ciudad de Santiago. (Tesis de pregrado). Santiago, Chile: Universidad de Chile.

Cultelli, Gabriela y Pamela Sosa (2018). La mercantilización de la fuerza de trabajo de la mujer: una visión desde la economía política. Economía D desarrollo, 160(2).

Departamento de Extranjería y Migración (2015). Estadísticas migratorias del Departamento de Extranjería y Migración 2015. Santiago, Chile: Ministerio del Interior y Seguridad Pública. 
Diálogo Político (2018). Adaptación a América Latina del índice MIPEX. Recuperado de https://dialogopolitico.org/debates/adaptacion-a-america-latina-del-indicemipex/.

El Dínamo (2019). Acción migrante rechazó procedimiento que expulsó a 114 extranjeros. Diario electrónico El Dínamo. Recuperado de https://www.eldinamo.cl/ nacional/2019/o2/21/accion-migrante-rechazo-procedimiento-que-expulso-a114-extranjeros/.

El Mercurio (2017). Capacitación a migrantes irregulares no existe en países líderes en el tema. Economía y Negocios, Diario El Mercurio. Recuperado de http://www. economiaynegocios.cl $/$ noticias $/$ noticias.asp?id $=400407$.

EMOL (2017). Muerte de Joane Florvil: Tribunal decreta que ciudadana haitiana no cometió el delito por el que fue detenida. Diario El Mercurio Online. Rescatado de: https://www.emol.com/noticias/Nacional/2017/11/22/884472/Muerte-de-JoaneFlorvil-Tribunal-decreta-que-ciudadana-haitiana-no-cometio-el-delito-por-elque-fue-detenida.html.

EMOL (2018). Lanzan en Chile la primera escuela gratuita de gastronomía para migrantes. Diario El Mercurio Online. Recuperado de https://vcm.emol.com/2843/ formacion/lanzan-en-chile-primera-escuela-gratuita-de-gastronomia-para-migrantes/.

Fraser, Nancy (2006). La justicia en la era de la política de identidad: redistribución, reconocimiento y participación. En Fraser y A. Honnerth ¿Redistribución o reconocimiento? Madrid, España: Ediciones Morata.

Frías, Daniela (2017). Construcción de la espacialidad de mujeres dominicanas en el campamento Ribera Sur de Colina, Santiago. (Tesis de magister). Santiago, Chile: Pontificia Universidad Católica de Chile.

Fuentes, José (2018). Nuevas territorialidades, el proceso de campamentación en la ciudad de Antofagasta. Revista, CIS 15(24): 97-112.

Fundación Techo (2015). Datos duros de una realidad muchísimo más dura. Informe de encuesta nacional de campamentos 2015. Santiago, Chile: Centro de Investigación social Techo-Chile.

Garretón, Manuel (2013). Neoliberalismo corregido y progresismo limitado: los gobiernos de la Concertación en Chile 1990-2010. Editorial Arcis CLACSO. Santiago, Chile.

Garza, Enrique (1997). El papel del concepto de trabajo en la teoría social en el siglo XX. Acta Sociológica, (20): 9-32.

Garza, Enrique (2001). Problemas clásicos y actuales de la crisis del trabajo. En Neffa, J. L. y Garza, E. (comp.) El trabajo del futuro. El futuro del trabajo. Buenos Aires, Argentina: CLACSO. 
Gavilán, Vivian (2015). Ser indio y ciudadano en el norte. Etnicidad y status de pertenencia a la comunidad nacional y política. Revista de Geografía Norte Grande (6o): 63-77.

Gissi, Nicolas, Carolina Pinto y Francisca Rodríguez (2019). Inmigración reciente de colombianos y colombianas en Chile. Sociedades plurales, imaginarios sociales y estereotipos. Estudios atacameños, (62): 127-141.

Gomes, Christianne y Rodrigo Elizalde (2009). Trabajo, tiempo libre y ocio en la contemporaneidad: Contradicciones y desafíos. Polis, 8(22): 249-266.

Gómez, Carlos (2014). Políticas públicas en educación en zonas fronterizas. Revista Justicia, 19(25): 171-179.

Held, David, Anthony McGrew, David Goldblatt y Jonathan Perraton (2002). Transformaciones Globales: Política, Economía y Cultura. México D.F., México: Oxford University Press.

Hernández, Ramón (2013). Identidad cultural o aculturación: el dilema de la escuela indígena en un contexto urbano. Revista de Investigación Educativa, 4, 19-24.

Hernández, Maite y Felix Villalba (2005). La enseñanza del español con fines laborales para inmigrantes. En P. García (Coord.): Glosas didácticas. Monográfico sobre didáctica intercultural y enseñanza de español segunda lengua en contextos no reglados, $15,74-83$.

Instituto Nacional de Estadísticas (2017). Características de la inmigración internacional en Chile, CENSO 2017. Santiago, Chile: INE.

Instituto Nacional de Estadísticas y Departamento de Extranjería y Migración (2019). Estimación de personas extranjeras residentes en Chile al 31 de diciembre de 2018. Santiago, Chile: INE y DEM.

Kogan, Irena (2016). Integration policies and immigrants' labor market outcomes in Europe. Sociological Science, (3): 335-358.

Larraguibel, Denis (2017). Educación para la diversidad cultural. Experiencias y aprendizajes de iniciativas en escuelas de la I región de Tarapacá. (Tesis de magister). Santiago, Chile: Universidad de Chile.

Ley N²0370. Diario Oficial de la República de Chile, Santiago, Chile, 12 de septiembre de 2009.

Ley $\mathrm{N}^{\circ}$ 20845. Diario Oficial de la República de Chile, Santiago, Chile, 15 de junio de 2015.

Luján, María (2009). Globalización neoliberal, migraciones y racismos. XXVII Congreso de la Asociación Latinoamericana de Sociología de la Universidad de Buenos Aires. Buenos Aires, Argentina: Asociación Latinoamericana de Sociología. 
Madariaga, Lissette (2020). El sueño de viajar y la realidad de habitar Santiago de Chile: migración haitiana en espacios laborales segregados y el racismo como una relación social. (Tesis doctoral). Universidad de Granada, España.

Malgesini, Graciela y Carlos Giménez (200o). Guía de conceptos sobre migraciones, racismo e interculturalidad. Madrid, España: Editorial Catarata y Consejería de Educación de la Comunidad de Madrid.

Madero, Ignacio y Claudia Mora (2011). Capital Social e Inclusión Laboral: Una aproximación a las trayectorias de ascendencia laboral de migrantes peruanos en Chile. Polis, 10(29): 147-163.

Mateo, María (1995). Enseñanza del español a inmigrantes. Datos empíricos y propuestas teóricas. Revista REALE, 3, 117-127.

Matta, Camila (2017). La colaboración interdisciplinar: un desafío en las clínicas jurídicas de migrantes en Chile. Revista Trabajo Social (92): 1-9.

Meninato, Pablo y Gregory Marinic (2019). Nuevas tácticas de intervención urbana en asentimientos informales en Latinoamérica. AULA Revista de Humanidades y Ciencias Sociales, 64(4): 21-31.

Ministerio de Desarrollo Social (2017). Síntesis de resultados encuesta CASEN Inmigrantes. Santiago, Chile: Ministerio de Desarrollo Social.

Ministerio de Educación (s.f.). ¿Cómo puedo validar estudios si soy extranjero? MINEDUC. Recuperado de https://epja.mineduc.cl/validacion-de-estudios/puedovalidar-estudios-extranjero/.

Ministerio de Salud (2018). Herramientas de facilitación lingüistica para funcionarios de salud en Kreyòl Ayisyen. Santiago, Chile: MINSAL.

Ministerio de la Mujer y Equidad de Género (2017). Estudio exploratorio sobre autonomías física y económica de las mujeres migrantes en las regiones Metropolitana, Tarapacá y Antofagasta. Santiago, Chile.

Mora, Claudia (2008). Globalización, Género y Migraciones. Polis, 7(20): 285-297.

Mora, María (2018). Política educativa para migrantes en Chile: un silencio elocuente. Polis, 17(49): 231-257.

Moraes, Natalia (2006). La perspectiva transnacional en el estudio de las migraciones y debate académico en España: A propósito del X congreso de migración en Almería. Revista Bibliográfica de Geografía y Ciencias Sociales, XI (667).

Muñoz, Héctor (1999). Política pública y educación indígena escolarizada en México. Cadernos Cedes, 19(49): 39-61. 
Muñoz, Ariela (2019). Expulsión de colombianos: Corte Suprema rechaza postura de INDH y da la razón al gobierno. Radio Biobio Chile. Recuperado de: https://www. biobiochile.cl/noticias/nacional/chile/2019/04/16/expulsion-de-colombianoscorte-suprema-rechaza-postura-del-indh-y-da-la-razon-al-gobierno.shtml.

Neffa, Julio (2015). Los riesgos psicosociales en el trabajo: contribución a su estudio. Buenos Aires, Argentina: Centro de Estudios Laborales CEIL-CONICET.

Oetzel, Ralf y Sergio Ruiz (2017). Movilidad humana, desastres naturales y cambio climático en América Latina. De la comprensión a la acción. Quito, Ecuador: Ministerio Federal de Cooperación Económica y Desarrollo, Alemania.

Ortín, Juan (2013). Migraciones: Desarrollos teóricos, evidencias empíricas y consistencias conceptuales. Las otras fronteras en la condición de migrante. Polis, 12(35): 165-182.

Peña, Antonio (2018). La migración forzada de Venezuela. Servicios de comunicación intercultural. Recuperado de https://www.servindi.org/actualidad-noticias/o6/10/2018/la-migracion-forzada-de-venezuela.

Pérez, Petra (1998). Antecedentes de la construcción teórica en antropología de la educación. Revista Interuniversitaria, 10(10): 205-231.

Peyser, Alexia y Juan Chackiel (1999). La identificación de poblaciones indígenas en los censos de América Latina. En Schkolnik (Ed.), América Latina: Aspectos conceptuales de los censos de 2000 (pp. 353-363). Santiago, Chile: CEPAL-CELADE.

Postigo, Marta (2011). El género y las dimensiones de la justicia: reflexiones sobre la teoría tridimensional de Nancy Fraser. Cuadernos Kóre. Revista de historia y pensamiento de género, 1(5): 44-79.

Rihm, Andrea y Dariela Sharim (2017). Migrantes colombianos en Chile: Tensiones y oportunidades en la articulación de una historia personal. Universitas Psychologica, 16(5).

Rojas, Héctor (2008). La importancia de las políticas públicas de formación en investigación de niños, niñas y jóvenes en Colombia, para el desarrollo social. Revista Latinoamericana de Ciencias Sociales, Niñez y Juventud, 6(2): 885-906.

Rojas, Nicolás y Claudia Silva (2016). Informe OBIMID. La Migración en Chile: Breve reporte y caracterización. Madrid, España: Observatorio Iberoamericano sobre Movilidad Humana, Migraciones y Desarrollo.

Ruíz, Felipe (2016). Superexplotación de la fuerza de trabajo en América Latina: consideraciones teóricas. Izquierdas (30): 236-257.

Salgado, Flavio, Carlos Contreras y Lorena Albornoz (2017). La migración venezolana en Santiago de Chile: inseguridad laboral y la discriminación. Revista Internacional de Estudios Migratorios, 8(1): 81-117. 
Sánchez, César y Everlam Montibeler (2015). La teoría de valor trabajo y los precios en China. Economia e sociedade, Campinas, 24(54): 329-354.

Silva, Claudia (2006). ¿Cómo viven los inmigrantes irregulares sus procesos de integración en Chile?. Revista Trabajo Social, (73): 157-169.

Stang, Fernanda y Carolina Stefoni (2016). La microf ísia de las fronteras. Criminalización, racialización y expulsavilidad de los migrantes colombianos en Antofagasta, Chile. Astrolabio, (17), 42-8o.

Stefoni, Carolina (2011). Ley y política migratoria en Chile. La ambivalencia de la comprensión del migrante. En B. Feldman, L. Rivera, C. Stefoni y I. Villa (Comps.) La construcción social del sujeto migrante en América Latina. Prácticas, representaciones y categorías. FLACSO. Quito, Ecuador.

Stefoni, Carolina, Sandra Leiva y Macarena Bonhomme (2017). Migración internacional y precariedad laboral. El caso de la industria de la construcción en Chile. REMHU: Revista Interdisciplinar da Mobilidade Humana, 25(49): 95-112.

Stefoni, Carolina, Fernanda Stang y Andrea Riedemann (2016). Educación e interculturalidad en Chile: un marco para el análisis. Estudios Internacionales, (185): 153-182.

Thayer, Luis (2013). Expectativas de reconocimiento y estrategias de incorporación: la construcción de trayectorias degradadas en migrantes latinoamericanos residentes en la Región Metropolitana de Santiago. Polis, Revista Latinoamericana, 12(35): 259-285.

Thayer, Luis, María Córdova y Betania Ávalos (2013). Los límites del reconocimiento: migrantes latinoamericanos en la Región Metropolitana se Santiago de Chile. Perfiles Latinoamericanos, 21(42): 163-191.

Thomaz, Diana (2013). La migración haitiana tras la catástrofe. Revista Migraciones Forzadas, (43): 35-37.

Toledo, Gloria (2016). Propuesta didáctica para la enseñanza de español como segunda lengua a inmigrantes haitianos en Chile. Lengua y migración, 8(1): 81-103.

Veliz-Rojas, Lizet, Andrés Bianchetti-Saavedra y Marta Silva-Fernández (2019). Competencias interculturales en la atención primaria de salud: un desafío para la educación superior frente a contextos de diversidad cultural. Cadernos de Saúde Pública, 35(1): 1-11.

Villanueva, Alejandra (2014). Construcción del relato biográfico y proyecciones de vida. Versiones de la migración haitiana en Santiago de Chile. CLACSO. Buenos Aires, Argentina. 
Yufra, Laura (2013). Inmigrantes en formación: Estado de bienestar y promoción de los alzos sociales en el caso de formación para la inserción laboral de las personas inmigrantes en Barcelona. Revista Athenea Digital, 13(2): 301-309.

Yufra, Laura y Enrique Santamaría (2015). Aprendiendo los cuidados del hogar en contextos migratorios: ambivalencias, alianzas y distancias. Universitas Psychologica, 14(5): 1637-1647.

\section{Sobre los autores}

Diego Rival-Carrillo es Licenciado en Antropología y tesista en Fundación Kimntrum, se ha centrado en investigar las experiencias de migración de ciudadanos latinoamericanos a Chile, especialmente desde la óptica del trabajo. Correo Electrónico: diegorival@udec.cl. (D) https://orcid.org/0000-0002-2394-9169

Amanda Valenzuela-Valenzuela es Antropóloga Sociocultural y Magíster en Lingüística Aplicada de la Universidad de Concepción e Investigadora en Fundación Kimntrum, sus líneas de investigación están centradas en enfoque de género, comunidades de la diversidad sexual y el uso de metáfora conceptual para el análisis de cuestiones políticas y sociales. Correo Electrónico: avalenzuelav@kimntrum.org. https://orcid.org/0000-0003-4961-6976

Ricardo Cartes-Velásquez es Médico Cirujano, Cirujano Dentista y Magíster en Filosofía de la Universidad de Concepción, Psicólogo de la Universidad del Desarrollo, Master of Public Health de The Metropolitan Manchester Unversity, Doctor en Ciencias Médicas de la Universidad de La Frontera e Investigador de la Fundación Kimntrum, sus líneas de investigación se centran en equidad y bienestar social, particularmente en la comprensión de los fenómenos de malestar de grupos históricamente excluidos, así como en la búsqueda de soluciones a tales fenómenos. Correo Electrónico: rcartesv@kimntrum.org. (iD) https://orcid.org/0000-0001-5831-7324. 


\title{
CUHSO
}

Fundada en 1984, la revista CUHSO es una de las publicaciones periódicas más antiguas en ciencias sociales y humanidades del sur de Chile. Con una periodicidad semestral, recibe todo el año trabajos inéditos de las distintas disciplinas de las ciencias sociales y las humanidades especializadas en el estudio y comprensión de la diversidad sociocultural, especialmente de las sociedades latinoamericanas y sus tensiones producto de la herencia colonial, la modernidad y la globalización. En este sentido, la revista valora tanto el rigor como la pluralidad teórica, epistemológica y metodológica de los trabajos.

\author{
EDITOR \\ Matthias Gloël \\ CoOrdinadora EDITORIAL \\ Claudia Campos Letelier \\ Corrector de ESTILO Y DiSEÑAdor \\ Ediciones Silsag \\ Traductor, CORRECTOR LENGUA INGLESA \\ Aurora Sambolin Santiago \\ SITIO WEB \\ cuhso.uct.cl \\ E-MAIL \\ cuhso@uct.cl
}

LICENCIA DE ESTE ARTÍCULO

Creative Commons Atribución Compartir Igual 4.0 Internacional 